\title{
Students' understanding and skills on voltage and current measurements using hands-on laboratory and simulation software
}

\author{
Ishlah Rahman ${ }^{1}$ (D) Marlizayati Johari ${ }^{2}$
}

Received: 28 October 2021 / Accepted: 6 January 2022 / Published online: 11 January 2022

(c) The Author(s), under exclusive licence to Springer Science+Business Media, LLC, part of Springer Nature 2022

\begin{abstract}
Skills competency is important especially in vocational and technical education. Thus, the aim of this research was to develop the student conceptual knowledge and skills in electrical measuring device to equip the students the necessary skills to become competent and skilful Technologist/Technician. A mixed method data analysis was employed on the data for thirteen Diploma in Telecommunication and Systems Engineering students who participated in this study. Quantitative instruments such as pre-test and post-test were used to check students' conceptual knowledge on electrical measurement after the exposure of the hands-on or simulation laboratories. Video recordings were used to capture students' processes on conducting the electrical measurement for both interventions. Observation form and laboratory rubric were used to analyse the skills of the students. The observer comments were then classified according to thematic analysis. The findings indicated that the students demonstrated an improvement in their conceptual understanding and their skills competency in measuring current and voltage in electrical circuits.
\end{abstract}

Keywords Hands-on · Simulation · Electrical Engineering $\cdot$ Conceptual understanding

Marlizayati Johari

marlizayati.johari@ubd.edu.bn

1 School of Science and Engineering, Politeknik Brunei, Belait, Brunei Darussalam

2 Sultan Hassanal Bolkiah Institute of Education, Universiti Brunei Darussalam, Brunei Muara, Brunei Darussalam 


\section{Introduction}

\subsection{Local context}

Brunei Vision 2035 aims to turn Brunei into a nation widely recognised for the accomplishments of its well-educated and highly skilled people as measured by the highest international standard. To accomplish this goal, Politeknik Brunei is established as a higher education institution, which has a vision of "producing skilful and marketable graduates" and mission "To equip students with sustainable skills". The students are enrolled in Diploma in Telecommunications and Systems Engineering.

\subsection{Literature review}

Engineering education reform in the vocational and technical education emphasises innovative and constructivist views of teaching and learning that always promotes active learning environments, dynamic instructions, and science experiments (Ekmekci \& Gulacar, 2015). Hofstein and Lunetta (2004) define science laboratory activities as learning experiences in which students interact with materials and/or with models to observe and understand the natural world. In the case of simulation, teachers use special simulation software or trained actors to simulate real-life scenarios for students (Kolb \& Kolb, 2017). The latter is common in medical schools, and the former is normally realised in science or engineering subjects to complement students' theoretical learning.

According to Steger et al. (2020), there is evidence that hands-on laboratories play a crucial role in influencing the outcomes of student learning. They also acknowledged that computer simulated experiments are becoming popular for conducting laboratory experiments in technical and vocational education. One of the reasons is simulation laboratories can help cost savings compare to specialised laboratory equipment required in hands-on laboratories. Advantages of simulation includes; 1) the learner can change system parameters and observe the outcomes with no harmful or safety issues, and 2) eliminating faulty components and equipment (Taher \& Khan, 2015). Therefore, many high education institutions conduct simulation laboratory as a complement to hands-on laboratory (Balakrishnan \& Woods, 2013; Steger et al., 2017, 2020).

Few literature reported on distance laboratory as a suitable alternative for regular hands-on laboratory (Konak et al., 2014; Zine et al., 2018). This can be useful in today's COVID-19 pandemic situation the world is facing. Research outcomes from Corter et al. (2011) has shown that simulated and remote laboratories can work as effective as hands-on laboratory in promoting conceptual understanding, but they also reported that students' preference towards hands-on laboratories was high. Majority of research concluded that simulation is a suitable substitute for hands-on laboratory work. For instance, teaching course concepts and its application in simulated laboratory with hands-on laboratory has shown excellent results (Abdulwahed \& Nagy, 2009; Steger et al., 2020) provided with good instructional design of the laboratory (Ekmekci \& Gulacar, 2015). 
Munge et al. (2018) reported that learner participation is an important factor when learners learn by doing. In order for the learners to be active, hands-on or simulation task-oriented processes with direct experience were proposed (Domingues et al., 2010; Taher \& Khan, 2015; Blair, 2016; Seaman et al., 2017; Munge et al., 2018). Collaboration with other students is often encouraged to experience physical hands-on learning (Abdulwahed \& Nagy, 2009) and often leads to better conceptual understanding compared to individual learning (Bakr, 2015; Corter et al., 2011; Zhan et al., 2013). Blair (2016) identifies that the nature of knowledge construction in experiential learning is a social process that is like the work of Piaget and Vygotsky. Student doing simulation can experiment interactively with instant feedback and enable students the opportunity to try different options whereas, in hands-on laboratory, students sometimes make mistake of their design (Taher \& Khan, 2015). Constructive discussion among the learners happened through reflections to link their prior knowledge and experience. This helps to improve their skills and modify their conceptual understanding. The change in behaviour and attitude addresses the cognitive and physical aspect of the learner so that the learners construct better understanding for future experience. Students can think critically when they are engaged in the situation which can provide a broader life experience (Deringer, 2017; Fowler, 2008). However, there are studies have shown that unwillingness of students to participate in practical courses is one of the main problems in higher education (Kolb \& Kolb, 2006; Nooghabi et al., 2011).

\subsection{Aim and scope of the research}

The aim of the research is to develop the students' conceptual knowledge and skills in electrical measuring devices to equip the students with the skills to conduct electrical measurement properly depending on the settings and applications. It can also become a lifelong skill for the students which align with the 21CTL dimension and Brunei's Vision 2035. In real applications, the measuring devices might not be similar to the academic laboratory equipment. However, the skills and experiences in performing measurements and interpretation of data are very useful. They can also gain indirect skills such as circuit troubleshooting and analysis. The electrical measurements laboratories are to be conducted either in hands-on or simulation laboratories. The effects of hands-on or simulation laboratories in helping students learn the concepts are to be determined.

\section{Research questions}

There are two research questions (RQs) to determine the purpose of the study.

RQ1: Is there a difference in students' performance on electrical measurement after exposure to hands-on/simulation laboratory?

RQ2: How does hands-on or simulation affect students' learning on electrical measurement? 


\section{Methodology}

\subsection{Participants}

Thirteen students enrolled in Diploma in Telecommunication and Systems Engineering programme participated in this study. The age range of the students was between 15 to 30 years old. There were three students who were below 18 years old from the secondary school science stream subjects. Whereas, ten students were from technical schools who did not have science backgrounds but had transferable modules that related to the program.

Six students and seven students were assigned to hands-on laboratory session and simulation laboratory session respectively based on their pre-test result. There were 3 groups for each of the interventions. The groupings were designed in such a way that the high ability students were paired with the low ability students and the mid ability students were paired together.

\section{Research method}

Action research method was employed in this study. This is because this method usually used to address local level problems with the anticipation of finding solution or improvement in a form of collective and self-reflective inquiry (Altrichter et al., 2002) which fit the design of this study Thus, the action research model that was adapted in this study only had one cycle which consisted of 1) planning, 2) acting, 3) observing, and 4) reflecting stages (Fig. 1).

Fig. 1 Research methodology (adapted and taken from Altrichter et al., 2002)

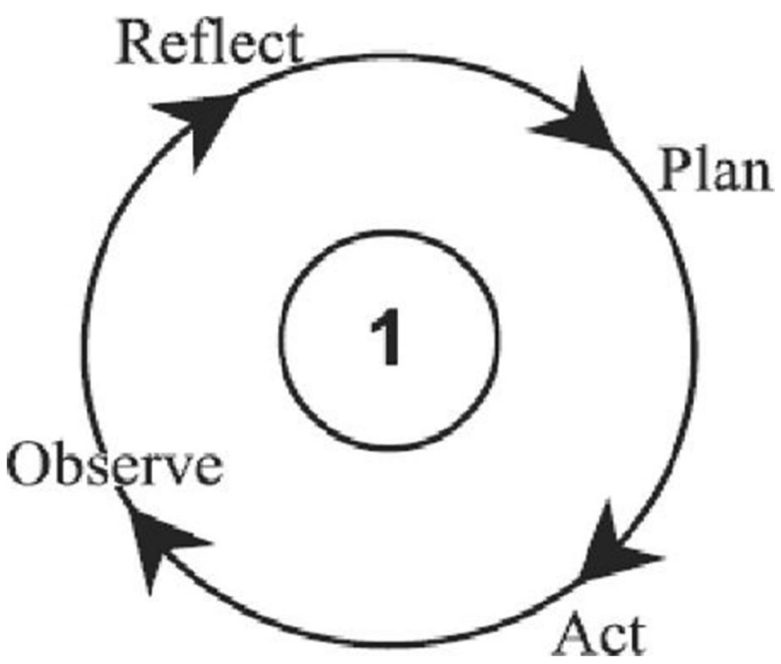




\subsection{Description of the intervention}

The researcher incorporated an instructional type of enquiry for the laboratory manual to determine the skills in electrical measurements. The intervention sheet had detailed step-by-step instruction. It contained several tasks related to series and parallel electrical measurements with fill-in the blank answer to record the students' findings. The laboratory manual was designed in such a way that the content and procedure were identical for both interventions i.e. hands-on and simulation. In the case of hands-on group, the students were required to set up the electrical circuit and conduct live measurements. Students were required to be able to use the DC power supply and breadboard. The importance of laboratory safety for electrical live testing was also briefed. The simulation group was required to construct the same electrical circuit using a simulation software called Multisim. The role of the instructor throughout the process for both activities was only to act as a facilitator.

\subsection{Instruments}

\subsubsection{Pre-test and post-test}

The questions comprised of four MCQs and a few short answer questions with schematic diagrams of electrical circuits provided. The questions were to assess students' knowledge on the concepts of voltage and current measurements. The validity of the questions had been validated by a subject expert. In addition, the validity of the questions also went through the institution's internal verification process.

\subsubsection{Survey}

The survey consisted of 10 items. 5 items on students' prior knowledge or experience on using ammeter and voltmeter either hands-on or simulation. 2 items consisted of Likert scale ranging from strongly agree to strongly disagree to gauge students' confident levels and skills in using ammeter and voltmeter after the interventions. The rest of the items were on the students' academic background.

\subsubsection{Video recording with observer form}

Video recording was used to observe the processes of electrical measurement conducted by the students to support observations. The researcher observed the observation processes using a rubric and observation form adapted from Mohamad (2017). The method of observation were followed but modified to suit this research context e.g. observing the students' processes in each of the tasks. This included comments made by the researcher during the observation. Thematic analysis was used to generate the codes and themes from the observer comments. 


\subsection{Data analysis}

Descriptive and inferential statistical analysis were used to analyse the quantitative data. Descriptive data was generated from the frequency of occurrence of the accuracy and wrongdoings during the observation processes of the students' conducting the activity i.e. hands-on or simulation activity. The students' processes were marked as correct, partially correct, or wrong. The frequencies of students' wrongdoings were recorded until the student gets the correct connections and measurements. The mark distribution was as follows: correct processes as 1 point, partially correct processes as 0.5 point and for wrong processes as 0 point. The accuracy processes were determined by the total points of the correct processes plus the partially correct processes. The total points were divided with the number of attempts made by the students throughout the activity and represented as a percentage. As to the inferential statistical analysis, parametric test i.e. paired t-test was used as the data distribution of the students' results from pre-test and post test do not violate the assumptions of the test.

Qualitative data were derived from the video transcriptions which included the observer comments were analysed for common codes and then the codes were categorised into themes according to Braun and Clarke (2006) thematic analysis.

\section{Results}

RQ1: IS THERE A DIFFERENCE IN STUDENTS' PERFORMANCE ON ELECTRICAL MEASUREMENT AFTER EXPOSURE TO HANDS-ON/SIMULATION LABORATORY?

The results from the pre-test $(M=7.08, S D=3.12$ and post-test $(M=11.8$, $\mathrm{SD}=3.19$ ) indicate that the students' exposure to hands-on or simulation laboratory resulted in an improvement to their performance on electrical measurement, $\mathrm{t}(13)=6.44, \mathrm{p}<0.001$. The effect size was found to be 0.78 (medium) based on the eta-squared formula. This indicated that the students' performance on electrical measurement has significantly improved after exposure to the intervention of handson or simulation laboratories.

Moreover, a survey was conducted after the interventions where two of the items were used to gauge the students' improvement level of measuring skills and confidence level in doing so were analysed. These two items used five points likert scale. The Cronbach's alpha reliability test of the two items is measured as 0.791 which gives acceptable internal consistency on the likert scale items (Tavakol \& Dennick, 2011).

$92.3 \%$ of the students agreed that the intervention improved their learning skills on electrical measurement while $7.7 \%$ remained neutral. In terms of confidence level after the intervention, $84.7 \%$ of the students agreed that they had gained confidence in their electrical skills, while $7.7 \%$ remained neutral and $7.7 \%$ did not respond. This descriptive statistic has shown that both hands-on and simulation laboratories positively affect the students' learning on electrical measurements. 
Table 1 Student processes (Hands-on)

\begin{tabular}{|c|c|c|c|c|c|c|c|c|}
\hline \multirow[t]{2}{*}{ Tasks } & \multicolumn{2}{|l|}{ Group 1} & \multicolumn{2}{|l|}{ Group 3} & \multicolumn{2}{|l|}{ Group 5} & \multicolumn{2}{|l|}{ Mean } \\
\hline & Accuracy & Wrong & Accuracy & Wrong & Accuracy & Wrong & Accuracy & Wrong \\
\hline Task 1 & $100 \%$ & $0 \%$ & $100 \%$ & $0 \%$ & $100 \%$ & $0 \%$ & $100 \%$ & $0 \%$ \\
\hline Task 2 & $73.1 \%$ & $26.9 \%$ & $80.8 \%$ & $19.2 \%$ & $65.6 \%$ & $34.4 \%$ & $73.2 \%$ & $26.8 \%$ \\
\hline Task 3 & $96.9 \%$ & $3.1 \%$ & $96.9 \%$ & $3.1 \%$ & $91.2 \%$ & $8.8 \%$ & $95 \%$ & $5 \%$ \\
\hline Task 4 & $88.6 \%$ & $11.4 \%$ & $62.5 \%$ & $37.5 \%$ & $74.1 \%$ & $25.9 \%$ & $75.1 \%$ & $24.9 \%$ \\
\hline Mean & $89.7 \%$ & $10.3 \%$ & $85.1 \%$ & $14.9 \%$ & $82.7 \%$ & $17.3 \%$ & $85.8 \%$ & $14.2 \%$ \\
\hline
\end{tabular}

Table 2 Student processes (Simulation)

\begin{tabular}{|c|c|c|c|c|c|c|c|c|}
\hline \multirow[t]{2}{*}{ Tasks } & \multicolumn{2}{|l|}{ Group 2} & \multicolumn{2}{|l|}{ Group 4} & \multicolumn{2}{|l|}{ Group 6} & \multicolumn{2}{|l|}{ Mean } \\
\hline & Accuracy & Wrong & Accuracy & Wrong & Accuracy & Wrong & Accuracy & Wrong \\
\hline Task 1 & $100 \%$ & $0 \%$ & $100 \%$ & $0 \%$ & $100 \%$ & $0 \%$ & $100 \%$ & $0 \%$ \\
\hline Task 2 & $71.4 \%$ & $28.6 \%$ & $75 \%$ & $25 \%$ & $65.6 \%$ & $34.4 \%$ & $70.67 \%$ & $29.33 \%$ \\
\hline Task 3 & $100 \%$ & $0 \%$ & $100 \%$ & $0 \%$ & $100 \%$ & $0 \%$ & $100 \%$ & $0 \%$ \\
\hline Task 4 & $94.4 \%$ & $5.6 \%$ & $100 \%$ & $0 \%$ & $100 \%$ & $0 \%$ & $98.13 \%$ & $1.87 \%$ \\
\hline Mean & $91.5 \%$ & $8.5 \%$ & $93.8 \%$ & $6.2 \%$ & $91.4 \%$ & $8.6 \%$ & $92.23 \%$ & $7.77 \%$ \\
\hline
\end{tabular}

RQ2: HOW DOES HANDS-ON OR SIMULATION AFFECT STUDENTS' LEARNING ON ELECTRICAL MEASUREMENT?

\subsection{Hands-on and simulation processes}

It was found that the hands-on group was able to select the correct ammeter range for their task as compared to the simulation group. This was based on the observations during one of the assigned tasks that required microAmpere range. The students in the hands-on group compare their readings of the ammeter with the theoretical calculation. Whereas in the simulation group, the ammeter automatically does the setting without the students intervention needed. Therefore, this skill can be lacking for the simulation group.

The accuracy of the students' processes for the hands-on group and simulation group were presented in percentage in Tables 1 and 2, respectively.

As can be seen from Tables 1 and 2, the simulation groups had a higher percentage of accuracy as compared to the hands-on group for Task 3 and Task 4. This included the overall performance of the simulation groups that had a higher percentage of accuracy (92\%) as compared to the hands-on groups (85.8\%). Therefore, for this study, comparing hands-on laboratory and simulation laboratory showed that simulation groups had a higher percentage of accuracy than the hands-on group.

Based on the thematic analysis, there were two main themes has emerged which are: 
(i) Positive processes that affects the learning of measuring devices

(ii) Negative processes that affects the learning of measuring devices

Table 3 summarised the codes, themes and associated percentages generated for both of the interventions.

As can be seen from Table 3, there were seven codes identified for hands-on laboratory and six codes identified for simulation laboratory. The only different code between the hands-on and simulation groups was Safety. It was observed in the hands-on groups only. This was due to the importance of safety in doing live electrical testing which was absent in the simulation groups. Furthermore, the percentage suggests that both hands-on and simulation laboratories have more positive effects compared to negative effects (56.5\% for hands-on and $53.3 \%$ for simulation). About 10 practical mistake processes recorded for hands-on laboratory groups were from setting the ammeter at the highest range. This was also observed in the simulation laboratory groups where 3 practical mistake processes were recorded for missing ground connection in the circuit.

The code of "theoretical accuracy" in both hands-on and simulation were $8.1 \%$ and $13.3 \%$ as in Table 3, respectively. This suggests that the student able to relate their prior knowledge for measuring voltage and current for a given circuit. The

Table 3 Percentage of the codes and themes of positive and negatives affects of learning electrical measurements

\begin{tabular}{|c|c|c|c|c|c|}
\hline Intervention & Codes & $\begin{array}{l}\text { Percentage } \\
\text { (Codes) }\end{array}$ & Themes & $\begin{array}{l}\text { Percentage } \\
\text { (Themes) }\end{array}$ & Total \\
\hline \multirow[t]{7}{*}{ Hands-on laboratory } & Theoretical accuracy ${ }^{1}$ & $8.1 \%$ & \multirow[t]{5}{*}{ Positive affects } & \multirow[t]{5}{*}{$56.5 \%$} & \multirow[t]{7}{*}{$100 \%$} \\
\hline & Practical accuracy ${ }^{2}$ & $12.9 \%$ & & & \\
\hline & Seek explanation ${ }^{3}$ & $9.7 \%$ & & & \\
\hline & Safety $^{4}$ & $16.1 \%$ & & & \\
\hline & Learn from mistakes ${ }^{5}$ & $9.7 \%$ & & & \\
\hline & Theoretical mistakes $^{6}$ & $6.4 \%$ & \multirow[t]{2}{*}{ Negative affects } & \multirow[t]{2}{*}{$43.5 \%$} & \\
\hline & Practical mistakes ${ }^{7}$ & $37.1 \%$ & & & \\
\hline \multirow[t]{6}{*}{ Simulation laboratory } & Theoretical accuracy ${ }^{1}$ & $13.3 \%$ & \multirow[t]{4}{*}{ Positive affects } & \multirow[t]{4}{*}{$53.3 \%$} & \multirow[t]{6}{*}{$100 \%$} \\
\hline & Practical accuracy ${ }^{2}$ & $23.3 \%$ & & & \\
\hline & Seek explanation $^{3}$ & $6.7 \%$ & & & \\
\hline & Learn from mistakes ${ }^{5}$ & $10 \%$ & & & \\
\hline & Theoretical mistakes ${ }^{6}$ & $10 \%$ & \multirow[t]{2}{*}{ Negative affects } & \multirow[t]{2}{*}{$46.7 \%$} & \\
\hline & Practical mistakes ${ }^{7}$ & $36.7 \%$ & & & \\
\hline
\end{tabular}

\footnotetext{
${ }^{1}$ Theoretical accuracy - Correct theory in electrical measurements

${ }^{2}$ Practical accuracy - Correct processes in doing electrical measurements

${ }^{3}$ Seek explanation - Request further explanation

${ }^{4}$ Safety - Correct settings of measurement is used

${ }^{5}$ Learn from mistakes - Correct processes after wrong processes done in previous task

${ }^{6}$ Theoretical mistakes - Wrong theory in electrical measurements

${ }^{7}$ Practical mistakes - Wrong processes in doing electrical measurements
} 
students have the opportunity to ask questions related to the learning objectives during the supplementary video presentation on voltage and current measurements. Students were able to adapt and apply relevant knowledge towards the concept of electrical measurement to different configurations of electrical circuit. Although it is observed few of the lower ability student needs to compare answers with their peers. Few of the students also require hints to be able to solve the example during the discussion. The theory has to be drawn on the whiteboard to help students to visualise the connection of the measuring devices. The process of learning may require significant amount of time as stated by Coker et al. (2017). This experience provides new level of conceptual understanding and the students can absorbed the knowledge.

The codes in Table 3 of "seek explanation" and "learn from mistakes" had similar percentage of $9.7 \%$ in the hands-on laboratory intervention. For simulation laboratory, the percentage is $6.7 \%$ and $10 \%$, respectively. This suggests that the students can relate their theory and reflect on it with relation to the situations. The experiences in video and discussion session also help with the reflective stage. The students have time to reflect on the new experience and link the experience with the prior knowledge to form a new knowledge (Kolb, 1984; Kolb \& Kolb, 2017). The students were observed by the researcher that they have used mobile devices seeking further information from the internet during the discussion and intervention. During hands-on intervention, the students were observed searching for voltmeter and ammeter connections from breadboard point of view whereas during simulation intervention, students were observed seeking information on how to conduct voltage and current measurements in simulation software. This help the students to enhance their ability to search for relevant information related to the learning objectives. It is evident in Task 1 that both the hands-on and simulation groups correctly drawn the connection of voltmeter and ammeter connections for a simple circuit with one resistor. The stage of reflective observation is very important for the students to link in with their prior knowledge and experience to move forward to the abstract conceptualisation stage.

The codes "theoretical mistakes" and "practical mistakes" in Table 3 help the student to have technical reasoning skills. Although this has negative effects in both interventions, it can help develop student discussion skills such as asking why, what and why. This stage may relate to the reflective observation stage. The overall percentage for negative effects for hands-on is $43.5 \%$ and for simulation is $46.7 \%$. From the discussion and feedback, the students have identified that the voltmeter and ammeter needs to be connected correctly to get correct results for voltage or current. The researcher also introduced the concept of assuming the voltmeter or ammeter as a resistor so that it is easy for the students to grasp the knowledge. Students can visualise connecting another resistor to a resistor in parallel or in series. The researcher asks the students to think and visualise such as: 1) Question A- "If two resistors are connected in parallel and replace one of the resistors as measuring device, what are you measuring?", and 2) Question B-“If two resistors are connected in series and replace one of the resistors as measuring device, what are you measuring?". Most of the students correctly answer question A and question B. This further guidance help the students deepen their theoretical knowledge about voltmeter and ammeter connections. Collaboration is an important aspect in the abstract conceptualisation 
stage in helping the student to work together and interact in a discussion (Kolb \& Kolb, 2017). This is why the students were grouped during the intervention. It is observed the students contribute, share ideas and give feedback to achieve the learning objectives. Although there was a case of one or two passive learners, the group able to overcome what was required in the learning objectives. The students' ability to make technical discussion and make decisions within the group is also observed in the video recording. Task 1 and Task 2 of the intervention worksheet supports the abstract conceptualisation stage where the students develop a theory from the knowledge gained through simple measurement and any wrongdoings enable the students to make some plans to change for future practice.

Almost all the groups in both interventions have improved their learning in measuring devices when the comments suggest that after Task 2 of the laboratory manual, the group is able to do Task 3 without major mistakes. As observed in Table 3, the "practical accuracy" dominates the percentage of the positive affects themes as $12.9 \%$ for hands-on and $23.3 \%$ for simulation. The tasks in the laboratory manual help the student develop further skills related to voltage and current measurements. The design experiments in Task 3 and Task 4 require the students to apply their prior knowledge and experience. The students need to adapt their knowledge during the experiences and apply to different configurations of the electrical circuit. The researcher designed the tasks to scaffold the activities so the student can deepen their knowledge and has critical thinking skills. It is observed during the intervention that the students use their critical thinking skills to tackle problem in the task and deliver what was required. Indirect skills in hands-on laboratory such as using the breadboard, adjusting the DC power supplyand Multimeter were also observed. This is supported that students get involved in doing new hands-on activities also develop unintentional skills (Félix-Herrán et al., 2019).

\section{Discussion}

Based on the findings of the analysis of the data collected demonstrated that both interventions i.e. hands-on laboratory and simulation laboratory has a positive effects on students' learning and skills in voltage and current measurements. This was in concurrent with a review done by De Jong et al. (2013) and Steger et al. (2020). There were many studies that showed positive significant differences in students' performance after being exposed to different laboratory learning environments, for example Abdulwahed and Nagy (2009) and Odutuyi (2014) in the field of chemistry and electrical laboratory by Steger et al. (2020). However this finding is in contradiction to the finding of a study done by Steenhuis et al. (2011). Although, this study investigated financial students' performance in examinations after using a financial game based simulation where the context of the game might not be related to the context of examination questions. Hence there was an issue of decontextualisation. So in this research, the laboratory manual design needs to be aligned with the theoretical concepts in engineering education to get a better performance from the students and to ensure the effectiveness of the laboratory (Balakrishnan \& Woods, 2013; Ekmekci \& Gulacar, 2015). Furthermore, Jasti et al. (2020) identified that 
student performance in the higher order of the Bloom's taxonomy has improved for the simulation group as compared to the hands-on laboratory group. This is supported by Potkonjak et al. (2010) where the simulation laboratory improves students' problem solving capabilities in robotic courses in mechanical and electrical engineering education. Heradio et al. (2016) provided a comprehensive literature review on the impact on the student performance in simulation laboratories where it revealed that the students' performance has improved after the interventions. In addition, the significance of simulation laboratories in electric circuits has been reported to help the students in learning and understanding concepts and practical questions during assessment (Saleheen et al., 2018). Amida et al. (2019) reported a positive impact on student performance in simulation based learning in understanding of Ohms law. However, my finding highlighted the limitation of the simulation group where the hands-on group has developed better awareness in selecting suitable ammeter range as compared to the simulation group. In addition, the element of safety was missing from the simulation group which is an important factor to be considered in real life setting.

Nonetheless, there are differences in processes between hands-on laboratory and simulation laboratory. Students' conceptual understandings in hands-on laboratory were limited because of the pre-requisite knowledge in using breadboard for prototyping. Although the working principle of breadboard was briefly conducted before the hands-on intervention, confusion was still evident and observed especially in Task 4 of the intervention. Further research needs to be done for the simulation groups but this issue is expected to be similar if they are allowed to do the hands-on laboratory. For simulation intervention, the students were exposed to the simulation software before they perform the simulation laboratory to have a high adoption level (Balakrishnan \& Woods, 2013). Schematic of the electrical circuit with its measuring devices available in the laboratory sheet is easy to follow for simulation compare to transferring the connection using a breadboard in hands-on laboratory. Literature has shown that hands-on laboratory can provides students with real data and real issues so that students can understand the role of hands-on experiments (Isaak et al., 2018; Morris, 2019). This is missing in simulation laboratory and reported as least effective than hands-on laboratory (Deringer, 2017; Fowler, 2008). However, with simulation laboratory, students can go beyond the objectives of the experiments and therefore positively impact students' learning (Bakr, 2015; Konak et al., 2014; Zhan et al., 2013). The two types of interventions have shown that both laboratories are different in many aspects but effective (Abdulwahed \& Nagy, 2009; Ekmekci \& Gulacar, 2015; Steger et al., 2020). Findings from Balakrishnan and Woods (2013) has indicated that hands-on laboratory and simulation laboratory complement each other and at some extend can be accepted as a substitute for hands-on experiments. It can also blend classroom theory with experiments (Konak et al., 2014). This is also supported by the teachers and students at Imperial College London (Chen et al., 2016). 


\section{Implication}

Like all educational research experiments, this study has implications that should be considered. The researcher has come across issues and difficulties in teaching voltage and current measurements to students. The researcher has devise a solution that each of the measuring devices can be treated as a resistor connected in parallel (for voltage measurement) and a resistor connected in series (for current measurement). The researcher hopes it could improve the teaching strategies and pedagogies so that the students are at the most beneficial for learning and understanding the concept.

The most encountered problem is the used of breadboard for hands-on laboratory. The researcher could overcome if there is time for pilot study and use other means of technology to explain the use of breadboard for circuit connection. It has been observed by the researcher that the ammeter or the resistors connected in the breadboard were short circuited because of confusion in the internal breadboard connection. Another way is to disassemble one breadboard to expose the internal connection so that the students can better visualise the internal connection and apply this knowledge in connecting circuit. The researcher believes that the results from the qualitative studies can be different if this process can be taught earlier before the intervention. For the simulation, students commonly forgot to include the ground connection of the circuit. Although the simulator has warning regarding this issue, the researcher feels that by including a ground symbol to the circuit schematics can help minimise this implication.

\section{Conclusion}

There is strong evidence $(\mathrm{t}=6.44, \mathrm{p}<0.001)$ that the intervention improves marks. In the pre-test and post-test data, the marks are improved on average of 4.69 marks. Hence, if other samples of marks are taken, the mean paired difference in marks is 4.69. Based on this quantitative analysis of the pre-test and posttest, the results suggest that there is statistically difference in marks after the student is exposed to either hands-on or simulation laboratories.

The quantitative and qualitative evidence from the observation and analysis of the six groups has revealed that there is a positive effect towards student learning in hands-on laboratory or simulation laboratory. Both interventions can be considered a potential method of teaching the students in better conceptual understanding on voltage and current measurements by experience. This statement is supported by the data on the group conducting the processes accurately. Two themes have been generated from the observation comments, and it shows that the intervention has more positive affects than negative affects towards the students' learning on the voltage and current measuring devices. The positive difference in the pre-test and post-test marks of the students also supports these findings. 


\section{References}

Abdulwahed, M., \& Nagy, Z. K. (2009). Applying Kolb's experiential learning cycle for laboratory education. Journal of Engineering Education, 98(3), 283-294.

Altrichter, H., Kemmis, S., McTaggart, R., \& Zuber-Skerritt, O. (2002). The concept of action research. The Learning Organization, 9(3), 125-131.

Amida, A., Chang, I., \& Yearwood, D. (2019). Designing a practical lab-based assessment: A case study. Journal of Engineering, Design and Technology, 18(3), 567-581.

Bakr, M. H. (2015). Teaching electronics for non electrical engineers using blended learning and experiential learning X R Kno P O, Proceedings of the Canadian Engineering Education Association (CEEA), 2-5.

Balakrishnan, B., \& Woods, P. C. (2013). A comparative study on real lab and simulation lab in communication engineering from students' perspectives. European Journal of Engineering Education, 38(2), 159-171.

Blair, D. J. (2016). Experiential learning for teacher professional development at historic sites. Journal of Experiential Education, 39, 130-144.

Braun, V., \& Clarke, V. (2006). Using thematic analysis in psychology. Qualitative Research in Psychology., 3, 77-101.

Chen, W., Shah, U., \& Brechtelsbauer, C (2016). The discovery laboratory - a student-centred experiential learning practical: part i - overview. Education for Chemical Engineers, 17. Institution of Chemical Engineers, 44-53.

Coker, J. S., Heiser, E., Taylor, L., \& Book, C. (2017). Impacts of experiential learning depth and breadth on student outcomes. Journal of Experiential Education, 40, 5-23.

Corter, J. E., Esche, S. K., Chassapis, C., Ma, J., \& Nickerson, J. V. (2011). Process and learning outcomes from remotely-operated, simulated, and hands-on student laboratories. Computers and Education, 57(3), 2054-2067.

De Jong, T., Linn, M. C., \& Zacharia, Z. C. (2013). Physical and virtual laboratories in science and engineering education. Science, 340(6130), 305-308.

Deringer, S. A. (2017). Mindful place-based education: Mapping the literature. Journal of Experiential Education, 40, 333-348.

Domingues, L., Rocha, I., Dourado, F., Alves, M., \& Ferreira, E. C. (2010). Virtual laboratories in (bio) chemical engineering education. Education for Chemical Engineers, 5(2), 22-27.

Ekmekci, A., \& Gulacar, O. (2015). A case study for comparing the effectiveness of a computer simulation and a hands-on activity on learning electric circuits. Eurasia Journal of Mathematics, Science and Technology Education, 11(4), 765-775.

Félix-Herrán, L. C., Rendon-Nava, A. E., \& Nieto Jalil, J. M. (2019). Challenge-based learning: An I-semester for experiential learning in Mechatronics Engineering. International Journal on Interactive Design and Manufacturing, 13(4), 1367-1383.

Fowler, J. (2008). Experiential learning and its facilitation. Elsevier, Nurse Education Today, 28, 427-433.

Heradio, R., de la Torre, L., Galan, D., Cabrerizo, F., Herrera-Viedma, E., \& Dormido, S. (2016). Virtual and remote labs in education: A bibliometric analysis. Computers and Education, 98, 14-38.

Hofstein, A., \& Lunetta, V. (2004). The laboratory in science education: Foundations for the twenty-first century. Science Education, 88, 28-54.

Isaak, J., Devine, M., Gervich, C., \& Gottschall, R. (2018). Are we experienced? Reflections on the SUNY experiential learning mandate. Journal of Experiential Education, 41, 23-38.

Jasti, N., Kota, S., \& Venkataraman, P. B. (2020). An impact of simulation labs on engineering students' academic performance: a critical Investigation. Journal of Engineering, Design and Technology.

Kolb, D. A. (1984). Experiential learning: Experience as the source of learning and development (Vol. 1). Prentice-Hall.

Kolb, A. Y., \& Kolb, D. A. (2006). Learning style and learning spaces: a review of multidisciplinary application of experiential learning theory in higher education. learning styles and learning: A key to meeting the accountability demands in education. 45-91.

Kolb, A. Y., \& Kolb, D. A. (2017). The experiential educator: Principles and practices of experiential learning. EBLS Press.

Konak, A., Clark, T. K., \& Nasereddin, M (2014). Using Kolb's experiential learning cycle to improve student learning in virtual computer laboratories Computers and Education, 72. Elsevier Ltd, 11-22. 
Mohamad, H. B. (2017). The impact of problem-based learning on students' competencies in technical vocational education and training. Aalborg University. Ph.d.-serien for Det Tekniske Fakultet for IT og Design, Aalborg Universitet.

Morris, T. H. (2019). Experiential learning-a systematic review and revision of Kolb's model. Interactive Learning Environments, 1-14.

Munge, B., Thomas, G., \& Heck, D. (2018). Outdoor fieldwork in higher education: Learning from multidisciplinary experience. Journal of Experiential Education, 41, 39-53.

Nooghabi, S. N., Iravani, H., \& Fami, H. S. (2011). A study on present challenges on experiential learning of university students (University of Tehran, The Colleges of Agriculture and Natural Resources, Iran). Procedia - Social and Behavioral Sciences, 15, 3522-3530.

Odutuyi, M. (2014). Effects of laboratory learning environment on students' learning outcomes in secondary school chemistry. International Journal of Arts \& Sciences, 08(02), 507-525 (2015)

Potkonjak, V., Vukobratovic, M., Jovanovic, K., \& Medenica, M. (2010). Virtual mechatronic/robotic laboratory - a step further in distance learning. Computers and Education, 55(2), 465-475.

Saleheen, F., Wang, Z., Picone, J., Butz, B. P., \& Won, C.-H. (2018). Efficacy of a virtual teaching assistant in an open laboratory environment for electric circuits. Advances in Engineering Education, 6 , $1-27$.

Seaman, J., Brown, M., \& Quay, J. (2017). The evolution of experiential learning theory: Tracing lines of research in the JEE. Journal of Experiential Education, 40, NP1-NP21.

Steenhuis, H. J., Grinder, B., \& De Bruijn, E. J. (2011). Simulations, assessment and student learning. International Journal of Information and Operations Management Education, 4(2), 99-121.

Steger, F., Nitsche, A., Miley, C., \& Schweiger, H. (2017). Laboratory learning : Hands-on versus simulated experiments. AAEE2017 Conference.

Steger, F., Nitsche, A., Arbesmeier, A., Brade, K. D., Schweiger, H. G., \& Belski, I. (2020). Teaching Battery Basics in Laboratories: Hands-On Versus Simulated Experiments. IEEE Transactions on Education, Early Access, 1-11.

Taher, M. T., \& Khan, A. S. (2015). Effectiveness of simulation versus hands-on labs: A case study for teaching an electronics course. $122^{\text {nd }}$ ASEE Annual Conference and Exposition, Conference Proceedings.

Tavakol, M., \& Dennick, R. (2011). Making Sense of Cronbach's Alpha. International Journal of Medical Education, 2, 53-55.

Zhan, W., Porter, J. R., \& Morgan, J. A. (2013). Experiential learning of digital communication using LabVIEW. IEEE Transactions on Education, 57(1), 34-41.

Zine, O., Errouha, M., Zamzoum, O., Derouich, A., \& Talbi, A. (2018). SEITI RMLab: A costless and effective laboratory in electrical engineering, International Journal of Electrical Engineering Education, 1-21.

Publisher's note Springer Nature remains neutral with regard to jurisdictional claims in published maps and institutional affiliations. 